\title{
Perancangan Mesin Pencacah Plastik Tipe Shredder dan Alat Pemotong Tipe Reel
}

\author{
Naufal Yudha Triadi, Budhi Martana*, Sigit Pradana \\ Program Studi Teknik Mesin, Fakultas Teknik, Universitas Pembangunan Nasional Veteran Jakarta \\ Jl. Raya Limo, Kecamatan Limo, Kota Depok 16515 \\ *E-mail: budhi.martana@upnvj.ac.id
}

\begin{abstract}
Abstrak
Plastik merupakan benda yang dapat mendukung kegiatan sehari-hari manusia dikarenakan sifat yang praktis dan tahan. Namun, plastik yang dibuang dapat mencemari lingkungan sekitar dikarenakan sifat plastik yang sulit terurai. Tujuan penelitian ini adalah untuk menghasilkan mesin pencacah plastik yang mampu mencacah sampah plastik dengan tipe shredder dan alat pemotong tipe reel. Proses perancangan dipilih berdsarkan penilaian yang telah ditetapkan. Plastik yang akan dicacah adalah plastik jenis PET (polyethylene terephthalate) dan HDPE (high density polyethylene). Material pisau AISI 304 dipilih untuk mencacah sampah plastik. Dari hasil rancangan dan perhitungan, ukuran mesin memiliki dimensi $1105.6 \times 1355.7 \times 600$, daya motor penggerak 3 HP serta memiliki putaran $1450 \mathrm{rpm}$ yang dibantu oleh elemen transmisi pulley dan $v$-belt tipe A. Komponen pencacah yang dipakai terdiri atas 14 buah shredder blade dan pisau pemotong reel berjumlah 9 dengan 2 buah bedknife. Komponen pisau shredder, pisau reel, dan rangka dianalisis menggunakan Finite Element Analysis untuk mengetahui keamanan desain yang dirancang.
\end{abstract}

Diterima: 27-06-2020; Direvisi: 25-08-2020; Dipublikasi: 01-09-2020

Kata kunci: high density polyethylene; polyethylene terephthalate; reel; sampah plastik; shredder

\section{Abstract}

Plastic is an object that can support human daily activities due to its character that is practical and resistant. However, wasted plastic can pollute the environment since it is difficult to be decomposed. The purpose of this study was to produce plastic chopper machine that is capable of chopping plastic waste with shredder type and reel type cutting tools. The design process is chosen based on a predetermined assessment. The kinds of plastic that are chopped will be PET (polyethylene terephthalate) and HDPE (high density polyethylene) plastic. AISI 304 material knife was chosen to chop up plastic waste. According to the results of design and calculation, the engine size has dimensions of 1105.6x1355.7x600, 3 HP motor drive power, and has a rotation of $1450 \mathrm{rpm}$ which is assisted by pulley transmission elements and v-belt type A. The chopper components used consist of 14 pieces of shredder blade and 9 blade reel cutters with 2 pieces of bedknife. The components of shredder knives, reel knives, and frames are analyzed using Finite Element Analysis to determine the safety of the planned design.

Keywords: high density polyethylene; plastic waste, polyethylene terephthalate, reel; shredder

\section{Pendahuluan}

Indonesia merupakan negara penyumbang sampah plastik terbesar nomor 2 di dunia, menurut Jenna R. Jambeck [1] dalam satu tahun Indonesia mengotori lautan dengan sampah sebanyak 0.48-1.29 juta ton. Jika dilihat dari jumlah sampah plastik yang dihasilkan setiap harinya, Indonesia berada di posisi 16 dunia, akan tetapi jika dilihat dari kesalahan manajemen dalam pengolahan sampah, Indonesia berada di posisi runner up. Selain dari jumlah penduduk Indonesia yang banyak dan menjadi faktor pengali jumlah sampah plastik, kesalahan manajemen dalam pengolahan sampah menjadi faktor utama permasalahan sampah plastik saat ini. Berdasarkan data Kementerian Lingkungan Hidup dan Kehutanan (KLHK), komposisi sampah didominasi oleh sampah organik, yakni mencapai $60 \%$ dari total sampah. Sampah plastik menempati posisi kedua dengan 14\% disusul sampah kertas 9\% dan karet 5,5\%. Sampah lainnya terdiri atas logam, kain, kaca, dan jenis sampah lainnya [2].

Salah satu dari banyak masalah yang dihadapi dunia saat ini adalah pengendalian limbah lingkungan. Selama lebih dari dua dekade, jumlah sampah plastik yang bertumpuk di tempat pembuangan sampah telah menjadi masalah lingkungan yang krusial. Sistem pengumpulan sampah plastik yang tepat tidak ada, dan orang-orang tidak dididik tentang masalah sampah plastik. Setiap rumah menghasilkan limbah dari plastik, mulai dari nilon bekas, botol plastik 
hingga wadah plastik besar seperti ember, jerigen, tong, dan sebagainya. Namun, sifat limbah plastik yang tidak dapat terdegradasi menimbulkan masalah besar karena limbah ini dapat bertahan lebih lama di lingkungan kita yang menyebabkan segala macam masalah.

Plastik adalah bahan yang terdiri dari berbagai padatan organik sintetis atau semi-sintetis yang dapat dicetak. Plastik biasanya adalah polimer organik dengan massa molekul tinggi dan sebagian besar polimer ini didasarkan pada rantai atom karbon saja atau zat lain seperti oksigen, sulfur, atau nitrogen juga. Plastik diproduksi oleh proses penyatuan satu atau lebih monomer seperti etilen, stirena vinil klorida bersama-sama, dan ini disebut sebagai polimerisasi.

Polimer adalah zat yang molekulnya memiliki massa molar tinggi dan terdiri dari sejumlah besar unit berulang yang disebut monomer. Polimer terjadi baik dalam bentuk alami maupun sintetis. Polimer sintetik yang biasa disebut plastik direproduksi secara komersial dalam skala besar dan memiliki berbagai sifat dan kegunaan. Karakteristik yang membedakan dari beberapa plastik terjadi ketika tulang punggung karbon dari molekul polimer sering berikatan dengan rantai samping yang lebih kecil yang terdiri dari unsur-unsur lain seperti klorida, fluor, nitrogen, dan silikon. Misalnya, ketika atom klorida menggantikan atom hidrogen di sepanjang rantai karbon, hasilnya adalah polivinil klorida. Ini adalah salah satu plastik paling serbaguna dan banyak digunakan di dunia.

Polyethylene Terephthalate (PET) adalah poliester asam tereftalat dan etilen glikol. PET merupakan plastik yang sangat kuat yang mudah dikenali karena terlihat transparan. Semua botol minuman yang mengandung soda merupakan plastik jenis PET. Plastik ini juga digunakan di banyak produk lain seperti guci, sisir, tas, tas jinjing, karpet dan tali. Barang-barang yang terbuat dari plastik ini biasanya didaur ulang. Baru-baru ini, PET sering didaur ulang menjadi benang untuk membuat pakaian. Plastik ini sedikit lebih rumit untuk dikerjakan, kami sarankan untuk memulai dengan plastik lain. High-Density Polyethylene (HDPE) biasanya digunakan untuk wadah makanan atau minuman. Barangbarang yang terbuat dari plastik dapat berfungsi sebagai wadah untuk susu, oli motor, sampo, botol sabun, deterjen, dan pemutih. Banyak mainan juga dibuat dari plastik ini.

Tabel 1. Properti Material PET dan HDPE

\begin{tabular}{cccc}
\hline Jenis Plastik & Ultimate Tensile Strength (MPa) & Yield Strength (MPa) & Modulus of Elasticity (GPa) \\
\hline PET & 38,8 & 64,2 & 3,14 \\
HDPE & 26,2 & 25,8 & 0,977 \\
\hline
\end{tabular}

Mesin penghancur plastik adalah mesin yang melakukan fungsi penghancuran plastik atau bahan plastik seperti botol plastik, ember plastik dan lain sebagainya menjadi butiran atau serpihan untuk daur ulang. Penelitian ini difokuskan pada desain mesin penghancur untuk menangani botol bekas atau ember bekas. Dari sudut pandang yang disebutkan di atas, penghancuran botol plastik untuk didaur ulang lebih murah daripada membuat botol dari bahan mentah, dan juga dapat membantu mengendalikan masalah pembuangan limbah yang merusak lingkungan khususnya di negara-negara berkembang. Untuk alasan ini, ada kebutuhan untuk perluasan program daur ulang plastik serta mesin yang lebih murah untuk menangani masalah yang terkait dengan pengelolaan limbah plastik terutama botol plastik yang memiliki berbagai aplikasi di seluruh dunia.

Pemotong tipe reel merupakan pemotong yang biasanya digunakan pada alat pemotong rumput konvensional. Mesin ini memiliki dua bagian utama, yaitu bagian penggerak dan bagian pemotong. Bagian penggerak merupakan bagian yang menggerakan komponen reel yang terhubung langsung dengan poros penggerak. Sedangkan cutting unit terdiri dari pisau yang berputar atau disebut dengan blade dan pisau yang diam biasa disebut bedknife. Jumlah blade dalam satu unit reel bervariasi. Semakin banyak pisau yang digunakan semakin sama variasi ukuran yang dihasilkan dari pisau tipe reel. 
Dalam melakukan kerjanya pemotong tipe reel ini memiliki prinsip sama dengan menggunting, tetapi pada pisau tipe reel terdapat satu pisau yang diam (bedknife) dan beberapa pisau yang disusun secara berputar (reel blade). Pisau reel (reel blade) berfungsi mendorong rumput menuju reel dan menjaga agar plastik selalu dalam keadaan posisi vertikal.

\section{Material dan Metodologi}

Metodologi yang digunakan adalah riset development, yang digambarkan seperti terlihat pada Gambar 1. Proses perancangan diawali dengan mengumpulkan informasi data kebutuhan dan informasi mengenai material yang akan digunakan dalam proses pembuatan mesin Seluruh syarat tersebut diharapkan dapat terpenuhi pada solusi akhir. Selanjutnya dilakukan proses perancangan konsep untuk menentukan spesifikasi produk berdasarkan spesifikasi kebutuhan.

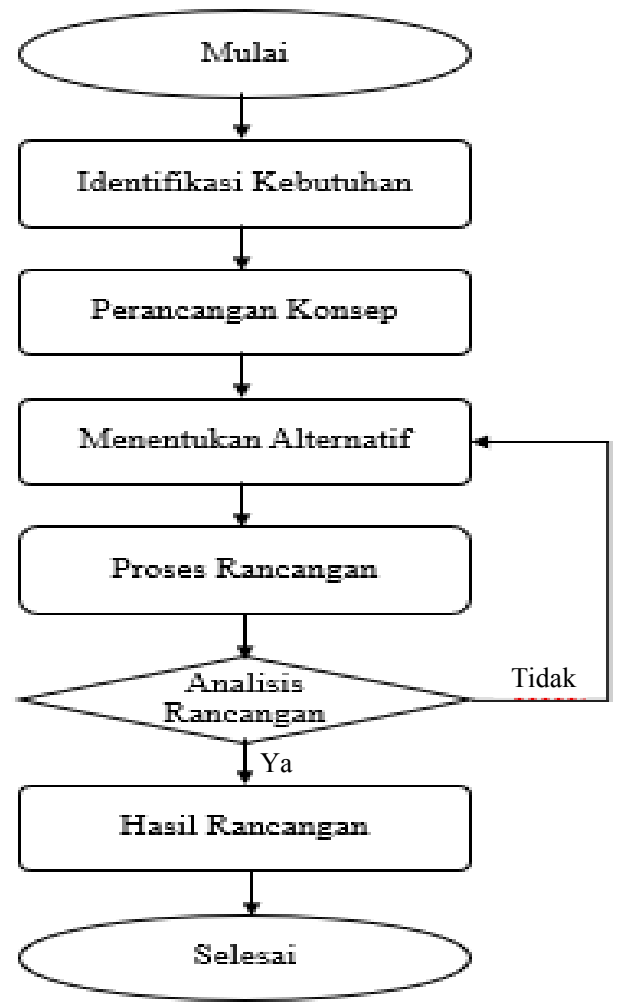

Gambar 1. Diagram Alir Penelitian

Tabel 2. Spesifikasi Mesin Pencacah Plastik

\begin{tabular}{|c|c|}
\hline Ketentuan & Persyaratan \\
\hline Produk Input & Sampah Plastik PET dan HDPE \\
\hline Produk Output & Cacahan Plastik \\
\hline Dimensi Output & $5-10 \mathrm{~mm}$ \\
\hline Dimensi Mesin & $500 \times 500 \times 500 \mathrm{~mm}$ \\
\hline Material Rangka & Baja \\
\hline Penggerak & Motor Listrik \\
\hline Daya & $<5 \mathrm{HP}$ \\
\hline Putaran & $1450 \mathrm{rpm}$ \\
\hline Kapasitas & $200 \mathrm{~kg} / \mathrm{jam}$ \\
\hline Pisau & 2 tipe Shredder dan Reel \\
\hline Material Pisau & Stainless Steel \\
\hline
\end{tabular}


Spesifikasi yang sudah terdefinisi merupakan acuan untuk dapat dikembangkan kembali dan melanjutkan tahap perancangan konsep. Konsep yang telah dirancang kemudian dianalisis berdasarkan kebutuhan mesin pencacah plastik. Rancangan konsep yang telah dianalisis selanjutnya dilakukan menentukan alternatif konsep, setiap alternatif dinilai berdasarkan kelebihan dan kelemahan/kekurangannya, sehingga diperoleh rancangan konsep terpilih. Penilaian alternatif fungsi keseluruhan dilakukan untuk mendapatkan desain yang sesuai dengan tuntutan pada tahap awal. Seluruh alternatif akan dinilai berdasarkan parameter pada Tabel 3.

Tabel 3. Properti Material PET dan HDPE

\begin{tabular}{lccccc}
\hline \multicolumn{5}{c}{ Parameter Penilaian } \\
\hline Nilai & 1 & 2 & 3 & 4 & 5 \\
Kriteria & Buruk & Kurang & Cukup & Baik & Sangat Baik \\
\hline
\end{tabular}

\section{Hasil dan pembahasan}

Dalam perencanaan mesin pencacah plastik ini diperlukannya daftar kebutuhan produk. Daftar kebutuhan produk merupakan pengembangan dari spesifikasi yang telah ditentukan sebelumnya, sehingga lebih terperinci. Daftar kebutuhan produk dibagi menjadi 7 bagian dari mesin pencacah plastik, antara lain: rangka, alat pencacah, transmisi, penampung, sumber penggerak, dan keamanan. Daftar kebutuhan mesin pencacah pencacah plastik tipe shredder dan alat pemotong tipe reel yang direncanakan diperlihatkan pada Tabel 4 berikut ini.

Tabel 4. Daftar Kebutuhan Mesin Pencacah Plastik

\begin{tabular}{|c|c|c|}
\hline \multicolumn{3}{|r|}{ Daftar Kebutuhan Pokok } \\
\hline Perubahan & $\mathbf{S} / \mathbf{H}$ & Uraian Kebutuhan \\
\hline & & Rangka: \\
\hline & $\mathrm{S}$ & a. Rangka memiliki dimensi maksimal 500x500x500 mm \\
\hline & $\mathrm{S}$ & b. Rangka kuat dalam menahan beban $300 \mathrm{~kg}$ \\
\hline & $\mathrm{S}$ & c. Bahan rangka dapat dicari dengan mudah dipasaran \\
\hline & $\mathrm{S}$ & d. Rangka terbuat dari besi \\
\hline & $\mathrm{H}$ & e. Rangka memiliki kemudahan pada saat proses manufaktur \\
\hline & & Alat Pencacah: \\
\hline & $\mathrm{S}$ & a. Alat pencacah terdiri atas 2 (dua) tipe, yaitu shredder dan reel \\
\hline & $\mathrm{S}$ & b. Alat pencacah memiliki kemudahan pada saat proses manufaktur \\
\hline & $\mathrm{H}$ & c. Alat pencacah memiliki kemudahan pada saat proses perakitan \\
\hline & $\mathrm{S}$ & d. Bahan alat pencacah dapat dicari dengan mudah dipasaran \\
\hline & $\mathrm{S}$ & e. Alat pencacah memiliki penyayat \\
\hline & & Transmisi: \\
\hline & $\mathrm{S}$ & a. Transmisi seefisien mungkin dapat menyalurkan daya pada saat proses produksi \\
\hline & $\mathrm{S}$ & b. Transmisi memiliki kemudahan pada saat proses perakitan \\
\hline & $\mathrm{H}$ & c. Komponen transmisi mudah dicari dipasaran \\
\hline & $\mathrm{H}$ & d. Jika ada kerusakan mudah diperbaiki \\
\hline & & Penampung: \\
\hline & $\mathrm{S}$ & a. Penampung terdapat pada bagian bahan masuk dan bahan keluar \\
\hline & $\mathrm{S}$ & b. Dimensi penampung memiliki keamanan terhadap operator \\
\hline & $\mathrm{H}$ & c. Penampung memiliki kemudahan pada saat proses manufaktur \\
\hline & & Sumber Penggerak: \\
\hline & $\mathrm{S}$ & a. Sumber penggerak berasal dari motor listrik \\
\hline & $\mathrm{S}$ & b. Motor listrik memiliki daya tidak lebih dari $10 \mathrm{HP}$ \\
\hline & & Keamanan dan Kenyamanan \\
\hline & $\mathrm{S}$ & a. Operator tidak harus membungkuk atau mengalami kesulitan \\
\hline
\end{tabular}


Naufal Yudha, dkk./Jurnal Rekayasa Mesin p-ISSN: 1411-6863, e-ISSN: 2540-7678

Vol.15|No.2|144-153|Agustus|2020

memasukkan bahan yang akan diproses

$\mathrm{H} \quad$ b. Sistem transmisi ditutupi

Dimana: $\mathrm{S}=$ Syarat (Harus dipenuhi); $\mathrm{H}=$ Harapan (Bisa dipenuhi atau tidak)

Spesifikasi yang sudah terdefinisi oleh daftar kebutuhan produk dapat menjadi acuan oleh penulis untuk dapat melanjutkan tahap mengonsep. Konsep rancangan ditentukan berdasarkan kebutuhan dari mesin sehingga dibuatnya alternatif fungsi untuk dipilih berdasarkan kelebihan dan kekurangan.

Tabel 5. Alternatif Solusi Sub Fungsi

\begin{tabular}{|c|c|c|c|c|}
\hline \multirow[t]{2}{*}{ No } & \multirow[t]{2}{*}{ Solusi Sub Fungsi } & \multicolumn{2}{|c|}{ Alternatif } & \multirow[b]{2}{*}{$\mathrm{C}$} \\
\hline & & $\mathrm{A}$ & B & \\
\hline 1 & Hopper & & & \\
\hline 2 & Rangka & & & \\
\hline 3 & Shredder & & & - \\
\hline 4 & Reel & & & - \\
\hline 5 & Penyaring & & & - \\
\hline 6 & Transmisi & & & \\
\hline 7 & Penampung Output & & & \\
\hline Var & Konsep & , & $\overline{\mathrm{BK}}$ & $\overline{\mathrm{BK}}$ \\
\hline
\end{tabular}

Perancangan sistematik lingkup permasalahan harus dibuat dengan luas yang tujuannya untuk memperoleh kemungkinan solusi yang sebanyak-banyaknya. Setiap kemungkinan harus diperiksa melalui prosedur yang tepat dan cermat, karena seiring solusi terbaik muncul setelah pengkombinasian yang bernilai dengan solusi yang bernilai tinggi, dengan mempertimbangkan (1) kesesuaian terhadap fungsi keseluruhan, (2) terpenuhinya tuntutan yang tertulis dalam daftar kebutuhan, (3) kebaikan dalam hal prestasi mesin dan kemudahan perakitan, (4) segi keamanan dan kenyamana, 
Naufal Yudha, dkk./Jurnal Rekayasa Mesin p-ISSN: 1411-6863, e-ISSN: 2540-7678

Vol.15|No.2|144-153|Agustus|2020

dan (5) kemungkinan untuk pengembangan lebih lanjut. Hasil dari kombinasi prinsip alternatif bagian keseluruhan (ABK) yang terdapat pada tabel 5 menghasilkan varian-varian sebagai berikut:
a. Varian ABK 1: 1A, 2A, 3A, 4A, 5A, 6A, 7A
b. Varian ABK 2: 1B, 2B, 3B, 4B, 5A, 6C, 7B
c. Varian ABK 3: 1C, 2C, 3B, 4B, 5A, 6C, 7B

Tabel 6. Penilaian Ideal

\begin{tabular}{|c|c|c|}
\hline \multirow[t]{2}{*}{ Aspek } & \multicolumn{2}{|c|}{$7 \mathrm{~A}$} \\
\hline & Bobot & Nilai \\
\hline Fungsi & 5 & 25 \\
\hline Konstruksi & 5 & 25 \\
\hline Pembuatan & 5 & 25 \\
\hline Perakitan & 5 & 25 \\
\hline Total & 20 & 100 \\
\hline
\end{tabular}

Seluruh varian fungsi dinilai berdasarkan aspek penilaian ideal.

Tabel 7. Penilaian Alternatif Varian

\begin{tabular}{lcccccc}
\hline \multirow{2}{*}{ Aspek } & \multicolumn{2}{c}{ ABK 1 } & \multicolumn{3}{c}{ ABK 2 } & \multicolumn{2}{c}{ ABK 3 } \\
\cline { 2 - 7 } & Kode & Nilai & Kode & Nilai & Kode & Nilai \\
\hline Hopper & 1A & 80 & $1 \mathrm{~B}$ & 65 & $1 \mathrm{C}$ & 60 \\
Rangka & 2A & 95 & $2 \mathrm{~B}$ & 80 & $2 \mathrm{C}$ & 80 \\
Shredder & 3A & 90 & $3 \mathrm{~B}$ & 75 & $3 \mathrm{~B}$ & 75 \\
Reel & 4A & 95 & $4 \mathrm{~B}$ & 75 & $4 \mathrm{~B}$ & 75 \\
Penyaring & 5A & 90 & 5A & 75 & $5 \mathrm{~A}$ & 75 \\
Transmisi & 6A & 85 & $6 \mathrm{C}$ & 70 & $6 \mathrm{C}$ & 60 \\
Penampung Output & 7A & 90 & $7 \mathrm{~B}$ & 70 & $7 \mathrm{~B}$ & 70 \\
Total & & 89,3 & & 72,9 & & 70,7 \\
\hline
\end{tabular}

Penilaian ABK berdasarkan aspek penilaian pada tabel 7 diatas dan data-data perbandingan variasi konsep yang ada, maka fungsi kombinasi yang paling ideal dari ke 3 variasi konsep adalah variasi ABK 1 .

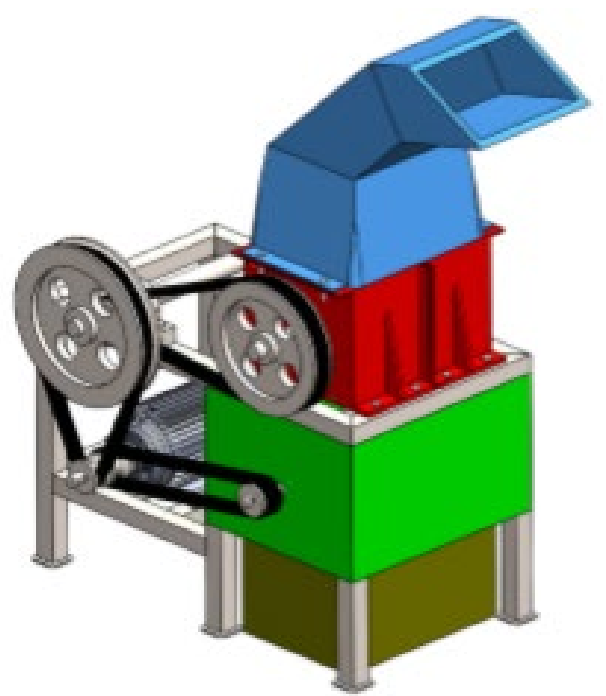

Gambar 2. Konsep yang Terpilih ABK 1 
Menentukan gaya:

$$
F c=0,5 \times\left(\frac{s^{2}}{\tan \varphi}\right) \times \tau_{b}
$$

Dimana: $\quad F c$ : gaya pemotongan pisau $(\mathrm{N})$

$$
\begin{aligned}
& \mathrm{S}: \text { Tebal bahan }(\mathrm{mm}) \\
& \tau \mathrm{b}: \text { Kuat geser bahan }(\mathrm{N} / \mathrm{mm} 2) \\
& \varphi: \text { Sudut kemiringan pisau }\left(^{\circ}\right)
\end{aligned}
$$

Gaya pemotongan pisau tipe shredder:

$$
F c_{\text {shredder }}=0,5 \times\left(\frac{10 \mathrm{~mm}^{2}}{1}\right) \times \mathbf{2 2 , 3 8 ~} \mathbf{N} / \mathbf{m m}^{2}=1119 \mathrm{~N}
$$

Gaya pemotongan pisau tipe reel:

$$
\text { Fc }_{\text {reel }}=0,5 \times\left(\frac{10 \mathrm{~mm}^{2}}{1}\right) \times 22,38 \mathrm{~N} / \mathrm{mm}^{2}=1119 \mathrm{~N}
$$

Menentukan daya:

$$
P=F c \times \pi \times D \times n \times f k \times \eta \times 0,2235.10^{-7}
$$

Dimana: $\mathrm{P}$ : Daya pemotongan pisau

F : Gaya pemotongan pisau

$\mathrm{n}$ : Kecepatan putar pisau

$\mathrm{fk}$ : faktor keamanan

$\eta:$ Efisiensi $(\%)$

$$
P_{\text {shredder }}=1119 \times \pi \times 240 \times 75 \times 1,2 \times 0,85 \times 0,2235.10^{-7}=1,44 \mathrm{HP}
$$

Dengan gaya pemotongan yang sama dengan shredder, maka asumsi daya pada pemotong tipe reel sama sebesar 1,44 HP. Maka jumlah daya pada kedua pisau tersebut sebesar: 1,44 HP + 1,44 HP = 2,88 $3 \mathrm{HP}$.

Menentukan besar puli:

Tabel 8. Data Perencanaan Puli

\begin{tabular}{clc}
\hline No. & \multicolumn{1}{c}{ Parameter } & Data Perencanaan \\
\hline 1 & Putaran poros motor & $1450 \mathrm{rpm}$ \\
2 & Putaran poros reel & $1450 \mathrm{rpm}$ \\
3 & Putaran secondary shaft & $300 \mathrm{rpm}$ \\
4 & Putaran poros shredder & $75 \mathrm{rpm}$ \\
5 & Diameter puli motor dan reel & $75 \mathrm{~mm}$ \\
6 & Diameter secondary puli shaft & $362,5 \mathrm{~mm}$ \\
7 & Diameter puli shredder & $300 \mathrm{~mm}$ \\
\hline
\end{tabular}

Finite Element Analysis (FEA): 
Naufal Yudha, dkk./Jurnal Rekayasa Mesin p-ISSN: 1411-6863, e-ISSN: 2540-7678

Vol.15|No.2|144-153|Agustus|2020

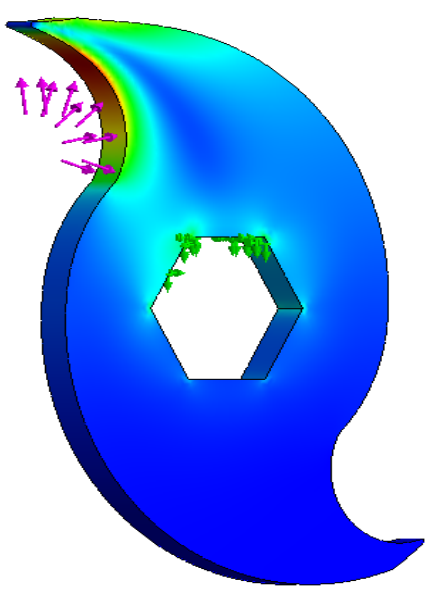

von Mises $\left(\mathrm{N} / \mathrm{m}^{\wedge} 2\right)$

Gambar 3. Von Mises Shredder Blade

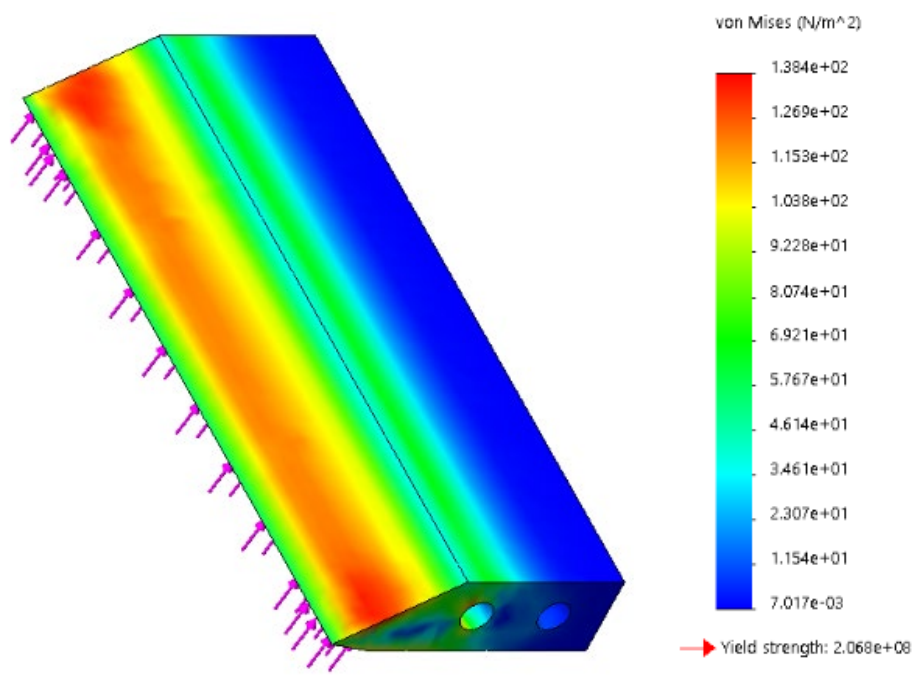

Gambar 4. Von Mises Reel Blade

Berdasarkan hasil Finite Element Analysis (FEA) seperti yang diperlihatkan pada gambar 3 dan gambar 4, diperoleh komponen pencacah yang dipakai terdiri atas 14 buah shredder blade dan pisau pemotong reel dengan jumlah 9 dengan 2 buah bedknife, sehingga diketahui keamanan desain yang dirancang.

Untuk menghitung bahwa desain yang telah dibuat dapat dikatakan aman maka, dapat dicari tegangan yang diijinkan kemudian dibandingkan dengan tegangan dari material yang digunakan. Berikut perhitungan untuk mengetahui kekuatan dari Shredder Blade, Reel Blade, dan rangka:

\section{$\frac{\text { Yield Point }}{\text { Factor of Safety }}=$ Allowable stress}

Untuk AISI 3014 nilai yield strength sebesar $215000000 \mathrm{~N} / \mathrm{m}^{2}$.

Shredder blade: (Factor Safety yang digunakan $=8$ untuk beban dinamis). 
$\frac{3,721 \times 10^{2}}{8}=46.5125 \frac{N}{m^{2}}<215000000 N / m^{2} \quad($ Aman $)$

Reel Blade: (Factor safety yang digunakan $=8$ untuk beban dinamis).

$\frac{1,384 \times 10^{2}}{8}=46.5125 \frac{N}{m^{2}}<215000000 N / m^{2} \quad($ Aman $)$

Untuk material st-37 nilai yield strength sebesar $235000000 \mathrm{~N} / \mathrm{m}^{2}$.

Untuk rangka: (Factor safety yang digunakan $=4$ ).

$\frac{4,043 \times 10^{6}}{4}=1010 \frac{N}{m^{2}}<235000000 N / m^{2} \quad($ Aman $)$

Berdasarkan FEA yang dilakukan, menunjukkan seluruh desain yang telah dibuat dapat dikategorikan aman dan dapat diaplikasikan untuk proses pencacahan. Diperoleh dimensi mesin pencacah plastik dengan panjang 1105,6 mm, lebar $600 \mathrm{~mm}$, dan tinggi $1355,7 \mathrm{~mm}$.

\section{Kesimpulan}

Desain mesin pencacah plastik ini merupakan sebuah pengembangan peralatan yang sudah ada untuk memenuhi kebutuhan masyarakat dalam menangani permasalahan sampah plastik. Desain yang dirancang adalah pemotong tipe shredder yang memiliki satu poros dengan pisau diam dan pemotong tipe reel menggunakan penggerak motor listrik dengan daya sebesar $3 \mathrm{HP}$, putaran pisau pemotong $75 \mathrm{rpm}$ pada shredder dan $1450 \mathrm{rpm}$ pada pemotong tipe reel. Sebagai tindaklanjut dari penelitian ini perlu dilakukan proses manufaktur dan produksi untuk mengetahui kapasitas cacahan plastik yang dapat dihasilkan.

\section{Daftar Pustaka}

[1] Jambeck, J.R., Geyer, R., Wilcox, C., Siegler, T.R., Perryman, M., Andrady, A., Narayan, R., and Law, K.L. Plastic Waste Inputs from Land into The Ocean. New York: Science Magazine. 2015.

[2] Kementerian Lingkungan Hidup dan Kehutanan. Peraturan Pemerintah Nomor 81 Tahun 2012 tentang Pengelolaan Sampah Rumah Tangga dan Sampah Sejenis Sampah Rumah Tangga. 2012.

[3] Junaidi, Nur, Ichlas, Nofriadi \& Rusmardi. Pengembangan Mesin Pencacah Sampah/Limbah Plastik Dengan Sistem Crusher dan Silinder Pemotong Tipe Reel. Jurnal Poli Rekayasa, Vol 10, No 2, pp. 66-73, 2015.

[4] Adhiharto, R., Komara, I.A., Annisa. Studi Rancang Bangun Mesin Plastic Waste Shredder Dengan Kapasitas 15 Kg/Hari Dengan Aplikasi Metode VDI 2222. Jurnal TEDC, Vol 13, No. 3, pp. 292-304. 2019.

[5] Batan, I.M. Londen. Desain Produk. Inti Karya Guna: Surabaya. 2012.

[6] Azhari, C., Maulana, D. Perancangan Mesin Pencacah Plastik Tipe Crusher Kapasitas 50 kg/jam. Jurnal ISU Teknologi STT Mandala, Vol. 13, No. 2 pp. 7-14. 2018.

[7] Olukunle, T. A., Design Consideration of a Plastic Shredder in Recycling Processes. International Journal of Mechanical, Aerospace, Industrial, Mecahatronic and Manufacturing Engineering. Vol. 10. No. 11. pp. 18241827. 2016. 
[8] Anggraeni, N. D., Latief, A. E., Rancang Bangun Mesin Pencacah Plastik Tipe Gunting. Jurnal Rekayasa Hijau, Vol. 2, No, 2, pp. 185-190. 2018.

[9] Aniekan, Ikpe, Ikechukwu, Owunna, 2017. Design of Used PET Bottles Crushing Machine for Small Scale Industrial Applications. University of Benin: Nigeria.

[10] Auliya, Arridho Fadhil, 2018. Perencanaan Mesin Pencacah Plastik Dengan Pemotong Tipe Crusher. Universitas Syiah Kuala. Banda Aceh.

[11] Khurmi, R.S. \& Gupta, J.K., 2005. The Text Book of Machine Design. Eurasia Publishing House : New Delhi.

[12] Muthukumaran, dkk, 2017. Design And Farication Of Plastic Waste Shredder Machine. SNS College of Engineering: Coimbatore.

[13] VijayAnanth, dkk, 2018. Design and Fabrication of Plastic Shredder Machine for Clean Environment. VELS Institute of Science, Technology, and Advanced Studies: Chennai. 